\title{
LA CONSTRUCCIÓN DE UNA IMAGEN FEMENINA A TRAVÉS DEL DISCURSO MÉDICO ILUSTRADO. CHILE EN EL SIGLO XIX
}

\author{
"Su alma, sus sentidos, \\ todas sus facultades están hechas para el amor. \\ Fuera de ahí, ella no sabe, ni quiere, ni puede saber más". \\ (Luis Rodríguez Velasco respondiendo al discurso \\ en pro de la educación científica de la mujer \\ pronunciado por Eugenio María de Hostos)
}

De acuerdo a la teoría liberal clásica el nuevo pacto social que da origen a la comunidad política moderna es un contrato entre individuos iguales. Es además -según Carole Pateman- un contrato sexual porque consagra la marginación de las mujeres como sujetos políticos en razón de su sexo. Comienza así un proceso de subjetivación femenina, al que contribuirán todos los ámbitos de la sociedad: político, religioso, filosófico, y según este artículo, científico-médico. Es este último uno de los discursos menos historiografiados en nuestro país. La tesis central es que a partir del modelo médico imperante en la segunda mitad del siglo XIX, la mujer comienza a ser definida como "enferma". El objetivo de esta investigación es evidenciar el "modelo médico" que el cuerpo médico-científico propone para las mujeres chilenas ${ }^{2}$.

Palabras clave: mujer, médicos chilenos, género, histeria.

According to the liberal classic theory, the new social contract that initiates the political modern community is a contract between equal individuals. Furthermore, it is -according to Carole Pateman- a sexual contract because it settles the marginalization of women as political subjects by reason of their sex. So begins a process of feminine subjectivation to which every segment of the society will contribute: political, religious, philosophical and, according to this article, scientific-medical. This last is one of the less researched discourses in Chilean historiography. The central thesis is that from the medical model prevailing in the second half of the XIXth century, women start to be defined as "the diseased". The aim of this research is to reveal the "medical model" that the medical - scientific body proposes for Chilean women².

Key words: woman, medical chilean, gender, hysterics.

1 Candidata a Magíster en Estudios Latinoamericanos, Universidad de Chile. Correo electrónico: c.arayaibacache@gmail.com

2 Este artículo fue elaborado en el marco del Proyecto Fondecyt 1020929, del año 2001, "La incorporación de la mujer chilena a la opinión pública: de la educación a los derechos civiles y políticos, 1877-1949” a cargo de Ana María Stuven. 


\section{INTRODUCCIÓN: LA DISCUSIÓN PÚBLICA EN TORNO A LA NATURALEZA FEMENINA Y EL MODELO FEMENINO MÉDICO EN LA EUROPA DECIMONÓNICA}

La legitimación de la razón como principio fundamental del mundo moderno fue el primer paso de un largo camino de secularización social por el que transitarán todos los actores de la sociedad civil, incluida la mujer ${ }^{3}$. En Chile, hasta la segunda mitad del siglo XIX las mujeres habían estado relegadas exclusivamente al ámbito de lo privado. Su tránsito hacia lo público se dio en torno a la lucha por la secularización de la sociedad civil. Mientras para algunos jugaba un papel clave en la modernización del Estado, para otros debía asumir la defensa de la fe desde su rol tradicional de madre y esposa ${ }^{4}$. Desde ambas posiciones se impuso un modelo determinado de naturaleza femenina a partir del cual se definió el rol de la mujer en la sociedad. Es así como, de acuerdo a la naturaleza de su sexo, la mujer estaba preparada para asumir de manera más natural el papel de esposa, madre, defensora de la fe y de la familia.

La construcción de este modelo de naturaleza femenina se realizó a partir de argumentos religiosos, políticos, filosóficos y científicos. La tesis central del argumento científico fue sostener la desigualdad biológica de la mujer y su disposición natural a la sensibilidad, la maternidad y el sufrimiento ${ }^{5}$. A la creación de este modelo femenino contribuyeron tanto el positivismo como la teoría de la evolución de las especies de Charles Darwin ${ }^{6}$.

El positivismo dominó gran parte de la cultura europea en el siglo XIX. Aunque es una corriente de pensamiento que valida como único método de conocimiento el científico, sus manifestaciones se dejaron sentir en los planos filosófico, político, pedagógico e historiográfico y su método se aplicó sin distinciones al estudio de la naturaleza y de la sociedad ${ }^{7}$. De acuerdo al positivismo, los hechos empíricos son la única base del conocimiento y la racionalidad científica la única solución a los problemas de la humanidad. Las concepciones idealistas y espiritualistas de la realidad son concebidas como etapas primitivas en el progreso humano. El positivismo aspira a un orden social establecido al que solo puede llegarse a través de un

3 Según la teoría feminista, para los contractualistas sociales la sociedad civil es un espacio esencialmente masculino. Carole Pateman, The Disorder of Women. Democracy, Feminism and Political Theory, Stanford University Press, Stanford, 1984.

4 Ana María Stuven, "Modernidad y Religión en Chile. La imagen de la mujer y su rol social durante el siglo XIX", XIV Jornadas de Historia de Chile, Santiago, 2001.

5 Ver George Duby y Michelle Perrot, Historia de las mujeres. El siglo XIX. Cuerpo, trabajo y modernidad, Taurus Ediciones, Madrid, 1993. También Romeo de Maio, Mujer y Renacimiento, Mondadori, Madrid, 1988; Viola Klein, El carácter femenino. Historia de una ideología, Editorial Paidós, Buenos Aires, 1951 y Simone de Beauvoir, El segundo sexo, Ediciones Siglo Veinte, Buenos Aires, 1972.

6 Sobre el tema, Diana Veneros se ha explayado en "Consideraciones médicas decimonónicas en torno a género, salud y educación”, en Dimensión Histórica de Chile, N 10, 1993-1994. Veneros se refiere al papel que la medicina y la educación jugaron en la construcción del género femenino, centrándose en la época del cambio de siglo en Chile.

7 Giovanni Reale y Darío Antiseri, Historia del Pensamiento filosófico y científico, vols. 2 y 3 , Editorial Herder, Barcelona, 1995. 
saber afianzado. Estas ideas generaron el marco adecuado para el surgimiento de teorías científicas vinculadas con las ideas filosóficas. Una de ellas fue la teoría evolucionista.

La teoría darwinista fue una de las corrientes científico-filosóficas que mayor influencia ideológica tuvo a lo largo del siglo XIX ${ }^{8}$. La teoría que Darwin construyó no solo penetró las ciencias naturales sino que inspiró nuevas concepciones del hombre, de la mujer, de la vida, del tiempo y del espacio en campos tan diversos como los del pensamiento histórico, filosófico, sociológico y otros ${ }^{9}$. Una de las primeras y más importantes consecuencias que trajo el pensamiento evolucionista fue la expansión de la teoría científica al campo de lo moral y lo social; la otra fue la discusión acerca de la inferioridad biológica de la mujer.

A partir del análisis comparativo de las especies se consolidó la asociación entre tamaño y estructura cerebral y evolución ${ }^{10}$. Desde la imposición de este modelo los científicos europeos se obstinaron en observar aquello que era imposible de ver. Por ejemplo, según el estructuralismo evolucionista, en la región frontal del cerebro residían las funciones cerebrales superiores donde tienen origen los procesos intelectuales más elevados y abstractos; en consecuencia, la región frontal del cerebro masculino debía ser más prominente que su correspondiente femenina. Después de observar una considerable cantidad de cerebros masculinos y femeninos los científicos concluyeron que la región frontal era, en el hombre, relativamente mayor que en la mujer, donde era mayor la parietal. Cuando posteriormente se supo que la región frontal del cerebro no mantiene ninguna conexión especial con los procesos intelectuales superiores, se pudo reconocer objetivamente el hecho de que la mencionada región es relativamente más extensa en la mujer ${ }^{11}$. Se reconoce en este hecho aquel mecanismo -sugerido por Foucault- que transforma la teoría desde la ideología, al igual que el poder (masculino) origina o preserva una realidad deseada amparándose en conocimientos científicos.

El anterior es un ejemplo puntual de aplicación de la teoría darwinista en el campo científico y de su influencia en la construcción de un modelo femenino en Europa a partir de ella. Sin embargo, el evolucionismo extendió su influencia más allá de lo meramente biológico, contribuyendo a crear una teoría acerca del carácter femenino que ejercería una influencia más allá del siglo en la que fue creada y que permanece hasta hoy. Evolutivamente, explica la ensayista Viola Klein, tanto en el hombre, "como en los machos en general, hay una tendencia orgánica hacia la variación, al alejamiento del término medio; y en la mujer, como en las hembras en general, a pesar de que se hallan más fácilmente expuestas a las oscilaciones menores, aparece una tendencia, también orgánica, hacia la estabilidad y el conservatismo, lo cual supone una anormalidad disminuida" 12 .

\footnotetext{
8 Charles Darwin, El Origen del Hombre. Selección natural y sexual, Ediciones Diana, México,

Klein, op. cit., 63.

Darwin, op. cit., 112.

Klein, op. cit., 67.

2 Ibid., 72.
} 1969. 
Ya no en un plano fisiológico ni anatómico, pero sí netamente científico, la teoría psicoanalítica también contribuyó a la creación de una imagen de mujer pasiva e inmovilista. El conservadurismo femenino tendría origen en la temprana castración psicológica que experimentan las niñas. Para Freud, la pulsión fundamental del accionar humano, la libido, "de manera constante y regular, es de esencia macho, ya aparezca en el hombre o en la mujer"13.

A partir de las teorías científicas se construyeron modelos médicos concretos acerca de la salud y la enfermedad en la mujer. Una de las esencias de estos modelos fue establecer la existencia de una conexión fisiológica entre el sistema reproductor y el sistema nervioso ${ }^{14}$. Otro de los pilares de esta construcción científica fue la precariedad del límite entre la fisiología y la patología femenina, es decir, entre la normalidad y la anormalidad. En la mujer, naturaleza y enfermedad se confunden a lo largo de la vida. Los ciclos exclusivamente femeninos, como la menstruación, la pubertad, el embarazo, la lactancia, la menopausia, aun siendo procesos fisiológicos, de acuerdo al modelo imperante son capaces de provocar trastornos tan poco fisiológicos como la enajenación mental. En este precario límite se basa la ciencia para defender la idea de que la mujer está naturalmente dispuesta para un permanente estado nervioso ${ }^{15}$.

En resumen, el modelo científico-médico femenino propuesto en Europa se construye a partir de la inferioridad biológica y fisiológica de la mujer. No solo la religión, sino que ahora también la ciencia apoya la idea de la debilidad femenina. Para el médico, dicha debilidad se manifiesta en el cuerpo enfermo; para los defensores de la fe, en el cuerpo enemigo del alma y obstáculo para la salvación. En este punto confluyen tanto la sociedad profana como la religión, "los antropólogos y los médicos enseñan que la sensibilidad, las emociones, los impulsos, tan ricos entre las mujeres, son la fuente de cualidades indispensables para el buen funcionamiento de la sociedad"16.

\section{PRIMERA PARTE \\ LAS CORRIENTES CIENTÍFICAS ENTRE LOS MÉDICOS CHILENOS}

La mirada modernizante y secularizadora en Chile estuvo ligada desde siempre al devenir europeo. Médicos, intelectuales y políticos chilenos se inspiraron en las teorías de sus pares europeos, especialmente franceses, ingleses y alemanes.

En Chile, a partir de la segunda mitad del siglo XIX, las ideas positivistas, fundamentalmente ligadas a la filosofía positiva de Comte, comenzaron a influir el escenario político ordenándolo en dos bandos de carácter marcadamente confronta-

13 Beauvoir, op. cit., Tomo I, 63.

14 Carrol Smith-Rosenberg y Charles Rosenberg, "El animal hembra: puntos de vista médicos y biológicos sobre la mujer y su función en la América del siglo XIX”, en Mary Nash ed., Presencia y Protagonismo. Aspectos de la historia de la mujer. Barcelona, Serbal, 1984.

15 Duby,op.cit., 23 y 24.

16 Ibid., 15. 
cional. Por una parte, el liberal, que sostenía programas de reforma y modernidad, y por otra, el de "resistencia", de inspiración católica y ligado a la Iglesia ${ }^{17}$.

Así como el positivismo tuvo entre sus primeros adalides a los políticos, el darwinismo se hizo carne originalmente en humanistas y políticos. El investigador Bernardo Márquez Breton ha sostenido que en nuestro país diversos intelectuales aludieron a las cuestiones que el darwinismo planteaba, pero no estuvieron entre ellos "ni los científicos puros ni los dedicados a las ciencias aplicadas", sino más bien los hombres de letras del período vinculados al liberalismo ${ }^{18}$. Asimismo, el darwinismo se organizó en un campo antagónico; por un lado, los grupos tradicionales, "encabezados por una legión de clérigos batalladores" y, por otro, representantes del liberalismo como Diego Barros Arana, Valentín Letelier y Luis Arrieta Cañas ${ }^{19}$.

Sin embargo, por las características ideológicas que marcan el desarrollo del pensamiento decimonónico no es posible hacer una distinción tan evidente entre hombres de letras y representantes de las ciencias puras. Los médicos chilenos, especialmente a partir de la segunda mitad del siglo XIX, tuvieron amplia participación en el sector político y humanista. Destacados y numerosos médicos fueron diputados por extensos períodos, y otros como Augusto Orrego Luco, Ramón Allende Padín, Sandalio Letelier y Adolfo Murillo, miembros de la Sociedad Médica, fueron fundadores de la Academia de Bellas Letras creada en 1873 por José Victorino Lastarria, introductor del positivismo en Chile ${ }^{20}$.

Haciendo la distinción anterior, la instauración de la medicina en Chile como disciplina académica y científica sí estuvo ligada fundamentalmente al surgimiento del positivismo. Si durante el período colonial, la incipiente medicina estuvo supeditada a los lineamientos de la Metrópoli, con el advenimiento de la república los cánones médicos comenzaron a ser impuestos desde Francia. El positivismo europeo le dio a la medicina el rigor científico que necesitaba para validarse como saber entre la sociedad chilena. El médico e historiador de la medicina chilena, Ricardo Cruz Coke, sostiene que en Chile la medicina "nació con el apellido de positivista" 21.

Los artículos aparecidos a lo largo de la segunda mitad del siglo XIX en la Revista Médica de Chile, dan cuenta del impacto que las ideas evolucionistas provocaron entre los médicos chilenos. Asimismo, gran parte de ellos viajaron a Europa a estudiar con maestros de las corrientes en boga como Claude Bernard o Jean Charcot ${ }^{22}$. Rodolfo Philippi -profesor de la escuela de medicina- había llega-

17 Miguel Vicuña Navarro, La emergencia del positivismo en Chile, Universidad Arcis, Centro de Investigaciones Sociales, Santiago, 1997, 4.

18 Bernardo Márquez Breton, Los orígenes del darwinismo en Chile, Editorial Andrés Bello, Santiago, 1982, 13 .

19 Ibid., 13.

20 Ricardo Cruz Coke, "Los profesores de la escuela de medicina y la historia política nacional, 1833-1983", en Revista Médica de Chile, $\mathrm{N}^{\circ} 11,1983,381$.

21 Ricardo Cruz Coke, Historia de la Medicina Chilena, Editorial Andrés Bello, Santiago, 1995, 360.

22 A su regreso, los médicos no solo difundieron las teorías darwinistas en lo relativo a la evolución de las especies, sino también las consecuencias aplicadas a las diferencias sexuales. Estas ideas originaron debates en la sociedad chilena sobre la capacidad de la mujer para ser educada. Diana Veneros, op. cit. 145 . 
do a Chile precisamente para regular la enseñanza y la práctica de las ciencias naturales enormemente influido por las ideas darwinistas ${ }^{23}$.

Las ideas evolucionistas y positivistas se encauzaron en el campo de la medicina a través de la explosión de los estudios de anatomía, neuroanatomía, biología y fisiología. Los avances en estos campos, especialmente en los dos primeros, provocaron una de las revoluciones más grandes en la historia de la medicina: la localización de las enfermedades, que consagró el método anátomo-clínico. La medicina, al creer factible determinar la localización exacta de las enfermedades en el organismo humano, vislumbró la posibilidad de hacer realidad el dominio del dolor humano a través de la ciencia. No había función ni enfermedad posible sin un órgano que la produjera. El médico y escritor Armando Roa apunta que "la pérdida del lenguaje en la afasia, significaba por ejemplo que la parte del sistema destinado al lenguaje hablado se había destruido sin que cupiera recuperación si esa destrucción no era salvada a tiempo. Se confundía así síntoma y centro habitual de expresión de una gran función, nada menos que con la función misma, como si a la elaboración del lenguaje no contribuyese el organismo y la sociedad entera" 24 .

Uno de los científicos que más notoriamente encarnó los postulados evolucionistas y positivistas fue el alemán Juan José Bruner. Bruner, socio corresponsal de la Sociedad Médico-Quirúrgica de Berlín y miembro de la Universidad de Chile, no solo desarrolló las disciplinas de histología, embriología y química, sino que además contribuyó al nacimiento de la psiquiatría nacional al escribir en 1857 su informe médico sobre el caso de Carmen Marín, La endemoniada de Santiago o el demonio en la naturaleza y la naturaleza del demonio. Con todo, la obra donde más claramente expone sus influencias humanistas, darwinistas y positivistas es $L a$ sustancia inmortal del organismo humano (1879). Allí señala que el alma,

lejos de ser inmaterial tiene por íntima base de su existencia a la materia, es decir, que es una substancia verdadera en el sentido naturalista y filosófico a la vez; hemos visto que esa substancia espiritual no ha nacido como un apéndice dentro del cuerpo y cerebro de algún animal o mono antropoide, sino que es un principio independiente, un protoplasma materialístico-espiritual, que desenvuelto en organismos humanos ha llegado, en su fabricación del cerebro, a la potencia de revelarse libremente en calidad de conciencia de sí y de lo de afuera; hemos visto que el hombre se distingue por consiguiente de los animales no solo por esta última manifestación, la espiritual, sino por toda la historia evolutiva de su principiosubstancia, es decir, por la íntima cualidad de su cuerpo entero ${ }^{25}$.

Bruner supo localizar en el cerebro el foco estructural de las enfermedades de la mente y del alma humana. Según cualquier punto de vista, "sea fisiológico, sea diabólico, siempre es preciso tomar el cerebro por el verdadero foco de las mani-

\footnotetext{
${ }^{23}$ Ricardo Cruz Coke, Historia de la Medicina..., op. cit.

24 Armando Roa, Demonio y Psiquiatría. Aparición de la conciencia científica en Chile, Editorial Andrés Bello, Santiago, 1974, 71.

25 La obra aludida se encuentra publicada en Armando Roa, Demonio y Psiquiatría..., op. cit., 35.
} 
festaciones mórbidas o inspiradas o como quiera que se las llame. (...) En el curso de estas indagaciones nos esforzamos por encontrar a todo trance en la masa cerebral, en esa materia gruesa, palpable y profana, el alma divina del hombre, con sus inspiraciones y vaticinios, con sus ideas y afectos" 26 .

Además de Bruner, los médicos chilenos aplicaron el positivismo y darwinismo en su práctica médica. Adolfo Valderrama, por ejemplo, indica en un artículo publicado en la Revista Chilena -revista científica y literaria de clara influencia positivista- que "no hay enfermedades sin alteración mental y que las afecciones sine substancia son una clase creada por las necesidades de una época en que la ciencia no había llegado a organizarse por completo ni había alcanzado los progresos de la época que atravesamos"27.

Augusto Orrego Luco, médico liberal, fundador de la cátedra de enfermedades nerviosas de la Universidad de Chile y discípulo del más famoso neuroanatomista francés del siglo XIX, Jean Charcot, dedicó gran parte de su carrera académica a fundar las bases científicas del conocimiento anatómico del cerebro y su relación con las enfermedades clínicas. En su obra, Circunvoluciones y Surcos del Cerebro Humano, publicada en 1879, adhiere a las teorías recientemente postuladas en Londres por Hughlings Jackson, de acuerdo a las cuales el sistema nervioso y la vida psíquica funcionan como una totalidad solidaria y se organiza en niveles evolutivos jerárquicos.

El positivismo y uno de sus vástagos, el desarrollo del método anátomoclínico, basado en la localización orgánica de las enfermedades, se expandió más allá de lo biológico y pretendió localizar en el cerebro las enfermedades neurológicas tanto como aquellas del ámbito psicológico, aventurándose a fijar en la masa cerebral las facultades morales y espirituales del individuo. Esta nueva manera de mirar al ser humano y a la enfermedad tuvo un marcado carácter científico y antropológico y se conoció con el nombre de Mimesis $^{28}$. En Chile fue introducida por Augusto Orrego Luco ${ }^{29}$.

Esta estrecha relación entre antropología y medicina permitió elaborar complejos mapas cerebrales donde se localizaban la amatividad, la maternidad, la responsabilidad. El mismo Augusto Comte elaboró un cuadro donde clasificó las facultades morales e intelectuales del individuo. Por ejemplo, el instinto sexual, el instinto maternal, el orgullo, la vanidad, pertenecen al primer grupo de facultades morales e intelectuales, es decir, al de afecciones, sentimientos o instintos ${ }^{30}$.

La corriente médica y científica en donde más eco tuvo el frenesí por la localización física de las enfermedades fue la frenología. La disciplina frenológica sostiene que tanto las facultades espirituales como morales de los individuos tienen su asiento en el cerebro. Para sus seguidores "[ella] ha probado y demostrado de una

26 Ibid., 353.

27 Adolfo Valderrama, "Apuntes para un libro. Sobre la responsabilidad moral", en Revista Chilena, Tomo III, $1875,273$.

28 Pedro Laín Entralgo, Medicina e Historia, Ediciones Escorial, Madrid, 1941.

29 Roa, Demonio y Psiquiatría ..., op. cit.

30 Manuel Fuentes, Lecciones de jurisprudencia médica. Tomo I, Elementos de Anatomía y Fisiología, Lima, 1876. 
manera que no consciente duda ni admite réplica (...), que las condiciones espirituales y modos de acción psicológica de las facultades mentales se manifiestan según sean las condiciones materiales y modos de acción fisiológica de los órganos y aparatos extracraneales e intracraneales del sistema nervioso, (...) en cuanto nuestro sistema nervioso se halla directa o indirectamente afectado por objetos externos o movimientos orgánicos internos, quedan análogamente afectadas las manifestaciones de todo nuestro espíritu"31.

La frenología, amén del campo médico, tuvo amplia repercusión en la jurisprudencia y en la criminología. Abundan las publicaciones sobre tipologías biológicas y psicosociales de los criminales, y numerosas tesis de estudiantes de derecho del siglo XIX que relacionan determinados tipos de conformación cerebral con delincuencia. El mismo Augusto Orrego, aun cuando en algunos períodos de su vida trata de mantener distancia de la frenología, al hacer la autopsia del Siete Lenguas, un famoso criminal de la época, declara que el cerebro de este posee una determinada organización que lo predisponía al crimen.

\section{SEgunda PARTE. EL MODELO MÉDICO FEMENINO CHILENO}

Los médicos chilenos del siglo XIX estudiaron las enfermedades femeninas en un manual del siglo XVIII ${ }^{32}$, herencia del enciclopedismo dieciochesco. No se conservan en el museo de la Facultad de Medicina de la Universidad de Chile ni ese ni ningún otro manual que aborde a la mujer de manera integral. Sin embargo, a través de algunos tratados de ginecología es posible indagar acerca de la relación que para los médicos chilenos y europeos existió entre histeria, epilepsia y el órgano femenino de la concepción, el útero.

Los casos clínicos que se conservan del siglo diecinueve fueron abordados desde una perspectiva casi exclusivamente técnica y científica. Sin embargo, se conserva un caso médico que no solo causó conmoción pública y fue objeto de polémicas en la prensa, sino que, de acuerdo a lo que sostienen tanto Armando Roa $^{33}$ como Enrique Laval ${ }^{34}$, fue el caso que inauguró la psiquiatría en Chile. Lo peculiar es que se trata de una mujer.

La paciente es una joven chilena llamada Carmen Marín, supuestamente endemoniada. El hecho salió a la luz pública en 1857 cuando la Iglesia Católica invita a varios facultativos chilenos a examinar a la paciente y les solicita redactar un informe respecto a si su mal tiene que ver con la posesión demoniaca o si se observa una enfermedad de características insólitas.

31 Mariano Cubí y Soler, Lecciones de Frenolojía. La Frenolojía y sus glorias, Carlos BaillyBailliere, Madrid, 1853, 911.

32 El manual al que se alude es Fisiología y patología de la mujer, de Baltasar de Vigueras, y está citado en Armando Roa, Demonio ..., op. cit., 57.

33 Ibid.

34 Enrique Laval, "El primer caso psiquiátrico publicado en Chile", en Revista de Psiquiatría, vols. 18,19 y 20, Stgo., 1953 a 1955, 66. 
El caso aludido constituye por sí solo una riquísima fuente para intentar elaborar un posible modelo médico de la mujer chilena decimonónica. En la tarea se utilizarán también las investigaciones de los médicos chilenos Eloísa Díaz, Manuel Segundo Beca, Ramón Ortiz Cerda, Augusto Orrego Luco, Víctor Körner y Jerónimo Letelier que tratan directamente el tema femenino. De acuerdo a estas fuentes se propone un modelo construido a partir de cuatro tópicos.

1. ...y el demonio era el útero

El determinismo orgánico uterino en el carácter y el ser femenino

Una de las teorías explicativas de la histeria es aquella que le dio nombre a la enfermedad. Histeria viene del griego hyster, que quiere decir útero. La histeria es concebida como una enfermedad "nerviosa [que] simula una enfermedad orgánica" 35 . Según la teoría uterina, es el útero el responsable de esta simulación y sería la mujer, por ende, la que sufriría las consecuencias orgánicas de la enfermedad. En la cuarta edición de su Tratado de Ginecología, los ingleses Hart y Barbour sostenían que se sabe muy poco de las alteraciones patológicas que se presentan en el histerismo, aparte de la inflamación crónica atrófica del útero descrita por Freud ${ }^{36}$.

En el origen y transmisión de la enfermedad jugaría un papel fundamental la "influencia de la herencia, que se confirma por la educación moral defectuosa que dan las madres histéricas y por el poder de imitación que se desarrolla en el histerismo confirmado"37. Es decir, la enfermedad, si bien tiene un origen anatómico, es aceptada como una enfermedad nerviosa que inclusive puede ser producto de una "educación viciosa o una vida desordenada, que estorba el desarrollo del organismo o agota sus fuerzas. En las mujeres es en general la falta de trabajo, la vida artificial y ociosa lo que genera esta susceptibilidad nerviosa" 38 . El mismo Orrego había expresado en una de sus clases sobre la histeria, que esta era una enfermedad patrimonio de la mujer elegante, coqueta y hermosa.

Otro de los síntomas orgánicos que se ven en la histeria y que también afectan a la mujer es el de la menstruación "escasa, irregular, a veces dolorosa y a veces completamente suprimida. Los padecimientos del ovario y del útero son comunes en las mujeres" 39 .

Para el tratamiento de la enfermedad era fundamental su localización orgánica; aquí es el útero el órgano enfermo responsable del permanente estado de nerviosismo en el que permanecen las mujeres. El solo poseer útero dispone a la mujer a una neurosis desde que inicia su vida fértil -“se han visto niñas que en la época menstrual son atacadas de una especie de enajenación mental"-40, hasta que concluye su ciclo reproductivo. Periódicamente, las mujeres evidencian "la influencia

35 Augusto Orrego Luco, "Neurosis Mímicas", en Revista Médica de Chile, v. 8, N 3, 1879, 105.

36 Berry Hart y Freeland Barbour, Tratado de Ginecología, s/editorial, Madrid, 1895, 814.

37 Ibid.

38 Orrego Luco, "Neurosis Mímicas", op. cit., 111.

39 Ibid., 107.

40 Ramón Ortiz Cerda, "Influencia del flujo menstrual sobre la salud y enfermedades de la mujer”, en Revista Médica de Chile, v. 2, Nos 7-9, 1874, 345. 
simpática del útero sobre los otros órganos de la economía, [a través] de las innumerables neurosis que acompañan a [las] perturbaciones menstruales. Las mujeres experimentan en este momento convulsiones, accesos de histérico, accesos de delirio, fenómenos catalépticos, accesos de locura, etc." 41 .

Uno de los médicos que participó en el examen de Carmen Marín fue Manuel Antonio Carmona, profesor de Ciencias Médicas y de Derecho y uno de los precursores del psicoanálisis en Chile. Su informe clínico es muy valioso para medir el estado de la psiquiatría chilena y la influencia de Cullen, Trousseau, Choman y del español Baltasar de Vigueras. Carmona entra en abierta polémica, incluso a través de la prensa, con el médico español Benito García, quien sostenía que Carmen Marín se encontraba endemoniada. Para el médico chileno, en cambio, era "el útero, aquella hidra monstruo, el único natural demonio que irradia sobre todo el sistema y muy particularmente sobre el cerebro sus quiméricas y vivísimas simpatías" 42 .

Carmona acompaña su informe con juicios históricos y teológicos que justifican su diagnóstico final, como cuando afirma que "la verdadera causa próxima de todos los fenómenos y ataques observados y aceptados por mí en la joven Carmen Marín, es una alteración primitiva, crónica sui generis de los ovarios, y complicada con una lesión consecutiva de todos los centros nerviosos y más claramente del eje o aparato cerebro-espinal; enfermedad evidentemente natural que tanto los maestros de la medicina, como el Diccionario de las Ciencias Médicas, clasifican como perteneciente al orden de las neuroses, y cuyo nombre propio es el de Histérico Confirmado, Convulsivo y en Tercer Grado"43.

Varios años más tarde, en 1884, el médico chileno Víctor Körner, presenta como tesis para optar al cargo de profesor extraordinario de la especialidad de ginecología, su monografía Exploración de la mujer. En ella, además de establecer como objeto de estudio de la naciente disciplina, las "particularidades físicas y morales" de las mujeres, plantea que los órganos genitales femeninos son "más voluminosos que en el hombre" y están también provistos "de nervios y vasos más voluminosos e importantes". Lo que estaría en completa "armonía con la función fisiológica más considerable que están destinados a ejercer y explica la influencia que el sistema genital de la mujer tiene sobre su constitución y el carácter moral del individuo" 44 .

Cuatro años más tarde, Eloísa Díaz, la primera médica chilena, en su memoria de título ratificaba la conexión uterina-ovárica con todos los centros nerviosos del organismo. A partir de la pubertad puede apreciarse "perfectamente cómo la actividad nerviosa que ha tenido su principio en los ovarios, se comunica no solamente a los plexos ováricos y uterinos sino que por medio del gran simpático se comunica a los nervios de todas las vísceras de la economía, y al centro encefálico mismo" ${ }^{45}$.

\footnotetext{
$41 \quad$ Ibid., 337.

${ }^{42}$ Manuel Carmona, Informe reproducido en Roa, Demonio ..., op. cit., 275.

43 Ibid., 314.

44 Víctor Körner, "Exploración de la mujer", en Anales de la Universidad de Chile, t. LXV, $1884,123$.

45 Eloísa Díaz, "Breves observaciones sobre la pubertad en la mujer chilena y de las predisposiciones patológicas propias del sexo", en Revista Médica de Chile, v. 16, Nos 7 y 8, 1888, 291.
} 
En consecuencia, el hecho fisiológico de tener útero predispone orgánicamente a la mujer a desarrollar en el curso de su vida episodios de histeria. Esta disposición física condiciona al mismo tiempo el carácter femenino. Es decir, a una "manera de ser física corresponde un estado mental que reproduce en la inteligencia, los sentimientos y la voluntad esos mismos caracteres de una excitabilidad fácil y desproporcionada al excitante" 46 .

2. ...un cerebro para amar

\section{La localización anatómica de la sensibilidad femenina}

La principal influencia sobre los médicos chilenos de la segunda mitad del siglo XIX fue la escuela experimental francesa. Aun cuando la frenología no corresponde a esta corriente sino más bien a una de origen español que se encontraba en retirada, abundan en todos los informes médicos sobre Carmen Marín, especialmente en el del ya aludido médico español, corresponsal del Instituto Médico de España, Benito García, los guiños a la escuela frenológica.

De acuerdo a la frenología las facultades morales, motoras e intelectuales tienen su asiento y su representación en el cerebro y pueden examinarse a través de la observación del cráneo. La ciencia frenológica ubicaba en complejos mapas cerebrales no solo las facultades motoras como la visualitividad, auditividad o lenguajetividad, sino también otras de carácter cultural como la ordenatividad, la conyugatividad, la filoproletividad, la superioritividad, la inferioritividad o la chistosividad. Al examen, cráneo femenino y masculino difieren físicamente y por ende pueden atribuirse a uno u otro sexo características culturales importantes en el diagnóstico médico.

El médico Mariano Cubí y Soler, propagador de la frenología en España, en sus Lecciones de Frenología sostiene que el órgano de la adhesividad se halla "por lo común mucho más desarrollado en la mujer que en el hombre. En efecto es cosa sabida que las mujeres son más cariñosas, adictas y afectuosas que los hombres. La mujer cuya vida ha de ser naturalmente doméstica, cuyas afecciones han de ser limitadas y fijas, cuyas armas deben depender más del amor, del apego, del cariño, de la devoción, de la sumisa dependencia que del valor o de la audacia, tiene la adhesividad, por lo común, mucho más desarrollada que el hombre. (...) La adhesividad en combinación con la conyugatividad, la amatividad y la filoproletividad, inspiran el impulso, cuyo instintivo designio, es la familia" 47 . Cosa similar ocurre con la circunspección, "más desarrollada en la hembra que en el macho o varón, cuya organización está en exacta correspondencia con el peculiar destino de los sexos. La mujer ha de ser timorata, más circunspecta, más temerosa que el hombre, para poder cuidar mejor de su reputación, de sus hijos, de su casa, de sus acciones, de su porte, según lo exigen el grado de escrupulosidad con que se observa y examina su conducta; puesto que

46 Orrego Luco, "Neurosis Mímicas", op. cit., 108.

47 Cubí y Soler, op. cit., 360. 
las mismas acciones que a veces nos admiran en el hombre por su audacia o arrojo, las reprobaríamos por su desenvoltura en la mujer" 48 .

Nótese la importancia que la escuela frenológica da a la localización física u orgánica de facultades como el bien, la dignidad o el amor a los hijos. Existe un órgano para el bien otro para la dignidad, etc. Es la representación corporal y científica del alma llevada al extremo. Nada alejado del evolucionismo y positivismo.

El examen frenológico del cráneo de Carmen Marín practicado por el doctor García, entrega los siguientes resultados:

(...) los órganos de los instintos (que nos son comunes con los animales) están medianamente desarrollados, como entre el grado $5^{\circ}$ y $7^{\circ}$; los órganos intelectuales, lo mismo los de observación que los de reflexión, están también, sin exceptuar uno, entre el $5^{\circ}$ y $8^{\circ}$ grado; los órganos morales lo mismo, entre el $5^{\circ}$ y $8^{\circ}$ [los frenólogos dividen el desarrollo de los órganos en 10 grados, el $1^{\circ}$ corresponde al idiotismo y el 10 al maximum que se conoce]. En particular el órgano de la amatividad o inclinación al otro sexo, está en el grado $6^{\circ}$; el de la filojenitura o amor a los hijos, en el $8^{\circ}$; la benevolencia (el órgano de hacer bien), la idealidad, la maravillosidad y la sublimidad en el $8^{\circ}$; la esperanza en el $7^{\circ}$; la veneración (el órgano religioso por excelencia) en el $6^{\circ}$; la causalidad en el $8^{\circ} ; \ldots$ el órgano de la dignidad lo tiene más desarrollado que el de la vanidad; inferior al $5^{\circ}$ grado no tiene ninguno. (...) Reflexiones.- Si hubiéramos de juzgar a doña Carmen Marín por su organización, diríamos que sería una buena esposa, excelente madre de familia, bastante moral, muy filantrópica, muy aficionada a lo bello, buena religiosa, con bastante capacidad para observar las cosas y más para reflexionar. (...) Completan este cuadro fisiológico cierta modestia y pudor que se revelan en su conversación al interrogarle sobre tantas cosas que he tenido que preguntarle ${ }^{49}$.

El examen físico practicado por Carmona concluye que "la región posterior u occipital del cráneo, donde residen, según la ciencia frenológica, los órganos de las facultades afectivas y de la fuerza física, se nota cualitativamente más desarrollada que la región anterior o frontal, asiento reconocido de las potencias intelectuales. Júntese a esto que el temperamento de la Marín es sanguíneonervioso, varonil y semiatlético y cualquier inteligencia podrá inferir a priori que el instinto ha de predominar más en ella que la razón, mientras que esta última no se sobreponga en fuerza del cultivo físico moral de la educación y de la costumbre" ${ }^{50}$.

\footnotetext{
48 Ibid., 623.
}

49 Relación hecha al Señor Arzobispo por el presbitero don José Raimundo Zisternas, Imprenta del Conservador, Santiago, 1857, 20 y 21.

50 Roa, Demonio y ..., op. cit., 240. 
3. ...naturalmente mujer

La estrecha relación entre los ciclos propios de la mujer y la enfermedad

Juan Carlos Luengo, analizando las causas de ingreso a la Casa de Orates de Santiago, se encuentra con que para el caso de las mujeres "el embarazo, la menstruación, el puerperio, el parto, la menopausia" eran frecuentemente invocadas en los documentos médicos 51 .

Entre las enajenadas mentales es frecuente encontrar hipertrofias del cuerpo del útero y alteraciones e inflamaciones del cuello uterino. Jerónimo Letelier, un joven aspirante a médico, escribía a fines del XIX que "las alteraciones en la menstruación, la supresión brusca del flujo menstrual produce muchas veces la enajenación, la cual desaparece cuando el flujo se restablece" ${ }^{52}$.

Con el inicio del ciclo reproductivo, desde la primera menstruación, comienza a definirse y manifestarse el temperamento femenino; la mujer comienza a hacerse "más pensativa y reservada, experimenta por primera vez ciertas sensaciones de las cuales no sabe darse cuenta, le ocasionan cierto embarazo, que se puede traducir por sus palabras y movimientos. Se despierta en ella el pudor" 53 . Desde pequeñas las niñas "son continuamente excitadas por las lecturas, las escenas teatrales, el baile, la sociedad con jóvenes de distinto sexo, etc., todas estas causas mantienen al sistema nervioso en una constante excitación, lo que hace apresurar el desarrollo de la joven" 54 .

\section{4. ... y vivirás con dolor \\ La condición de dolor y sacrificio asociada al ser biológico femenino}

Todos los informantes de la enfermedad de Carmen Marín concuerdan en que su carácter sanguíneo nervioso favorece su idiosincrasia uterina ${ }^{55}$. La doctora Eloísa Díaz sostiene que el temperamento de las mujeres es por "excelencia nervioso" y el de la mujer chilena es predominantemente "linfático nervioso", lo que la predispone para "los fenómenos de excitación de este aparato [reproductivo], [favoreciendo] al mismo tiempo ataques de histerismo o accidentes epileptiformes, precursores para la pobre mujer de una existencia de quejas y dolores" 56 .

La doctora Díaz vuelve a compadecerse del destino inexorable de su género cuando se pregunta por "una mujer linfática, nerviosa, que es el temperamento predominante en la mujer chilena, excesivamente excitable, de imaginación viva,

51 Juan Carlos Luengo, Enfermedad mental y aislamiento social. Tesis para optar al grado de licenciado en historia, Departamento de Ciencias Históricas, Facultad de Filosofía, Humanidades y Educación, Universidad de Chile, 1986, 182.

52 Jerónimo Letelier Grez, Contribución el estudio de las enfermedades mentales en Chile. Memoria de prueba para optar al grado de Licenciado en la Facultad de Medicina y Farmacia, Valparaíso, 1898, 8 .

53 Ortiz, op. cit., 315.

54 Ibid., 312.

55 Roa, Demonio y ..., op. cit., 372 .

56 Díaz, op. cit., 291. 
etc., ¿qué fenómenos irán a tener lugar en este ser cuyo sistema nervioso a la menor excitación sufre grandemente" 57 . En la introducción de su memoria, Eloísa Díaz había aludido a este destino encarnado en ella misma:

Sensible como mujer por estructura, tímida por consecuencia de su sensibilidad especial, acató ella [la mujer] inconsciente la prohibición injusta que se le imponía y temió traspasar la línea que le señalara como límite a su actividad social y al desarrollo de su inteligencia. (...) Al pretender obtener el título de Médico Cirujano, he pensado maduramente acerca de la grave carga que echaba sobre mis débiles fuerzas de mujer, rudo es el trabajo, lata es la ciencia, difícil la misión... pero, ¿es superior a la energía, a las dotes, de observación y a la inteligencia de las de nuestro sexo? No lo sé, pero siento aquí en el interior de mi ser que no me arrepiento hoy en el comienzo de la juventud, de la jornada que emprendí cuando era niña tierna y que me comprometo a seguir en medio de los afanes y vicisitudes de la vida ${ }^{58}$.

La construcción de modelos científicos sobre el cuerpo femenino, especialmente del vínculo establecido a partir de ellos entre sistema reproductor femenino y moralidad, tuvo consecuencias inmediatas en los tratamientos practicados a pacientes. A partir de estos modelos, Soledad Zárate ha analizado casos médicos de pacientes chilenas de fines del siglo XIX donde se justificaba la extirpación de órganos reproductivos femeninos ${ }^{59}$.

Además de estos tratamientos también se practicaban otros que si bien no eran mutilantes daban cuenta de la directa relación entre comportamiento y cuerpo femenino. Para la histeria uterina, el manual de Hart y Barbour - uno de los consultados por los estudiantes de medicina chilenos- sugiere que "los baños fríos son siempre beneficiosos" 60 . Si la histeria se complica con histero-epilepsia, "comprimir los ovarios" suele contener el ataque, lo que "se practica haciendo que la enferma se ponga en decúbito y aplicándole con fuerza el puño a la región" 61 .

Ernestina Pérez compartió con Eloísa Díaz en 1887 el mérito de ser la primera mujer chilena en recibir el título de médico cirujano. Al año siguiente la doctora Pérez recibió una beca para continuar sus estudios en Alemania. En 1910, en la clínica de la Universidad Real de Berlín, escribió Lecciones de Ginecología. A pesar de que el libro es un resumen de los últimos avances ginecológicos en Alemania, Francia, Inglaterra e Italia, tiene el mérito de ser la primera obra de esta materia escrita por una mujer chilena y editado en Berlín.

Si bien Lecciones de Ginecología está fuera del período analizado es válido aludir a algunos tratamientos que en él se proponen por la particularidad de la

57 Díaz, op. cit., 290.

58 Citado por Cristina Palma Prado y Emma Salas Neumann, "Presencia de la mujer en los estudios superiores de la Universidad de Chile", en Huella y Presencia, Ediciones de la Universidad de Chile, Editorial Universitaria, Santiago, 1992, 337.

${ }^{59}$ María Soledad Zárate C., “'Enfermedades de mujeres'. Ginecología, médicos y presunciones de género. Chile, fines del siglo XIX”, en Pensamientocrítico.cl, Revista Electrónica de Historia, $\mathrm{N}^{\circ} 1$, 2001 .

60 Hart, op. cit., 816.

61 Ibid., 818. 
obra, por la contemporaneidad de Pérez con algunos médicos que se incluyen en este estudio, y para insistir en la relación entre moralidad y fisiología en el modelo médico femenino decimonónico. Es así como en el libro de la doctora Pérez, para tratar el prurito vulvar -incluido dentro de las afecciones nerviosas localizadas en la vulva- se propone la "resección del clítoris en casos graves", ya que esta extirpación, "no ejerce ninguna influencia en la sensibilidad sexual ${ }^{62}$.

Tan importante como atender al tratamiento físico es "atender principalmente a la educación moral e intelectual de las niñas cuando hay tendencia al histerismo" 63 . El doctor Andrés Laiseca sostiene que para las mujeres es de gran ayuda mantenerse alejadas de los casos de histeria. En su informe sobre la enfermedad de Carmen Marín, agrega a su diagnóstico una indicación humanitaria al sugerir que otras mujeres no visiten a Carmen ya que "al ser esta enfermedad, como las otras enfermedades convulsivas, esencialmente contagiosa por imitación; y que por lo mismo están expuestas a contraerlas todas las personas, sobre todo del sexo femenino, que por una necia curiosidad, o por cualquier otro motivo, concurren a presenciar el penoso estado convulsivo de estos enfermos" 64 .

\section{CONCLUSIONES}

La medicina se organizó en Chile con un fuerte carácter científico pero también con una dimensión antropológica heredera del positivismo comteano. Basados en estas premisas construyeron un modelo científico social de fuerte peso hasta hoy en la sociedad chilena.

Los médicos chilenos desde su organización como cuerpo social y académico, y por qué no decirlo como cuerpo regulador de la salud del cuerpo y del alma, estuvieron imbuidos de las corrientes científicas europeas especialmente de origen francés.

La construcción del modelo médico femenino en Chile adquirió como es obvio las connotaciones anteriores. De gran similitud con el modelo europeo, los médicos chilenos sostuvieron la imagen de una mujer débil, sensible y de marcado temperamento nervioso.

La patología, la enfermedad, la anormalidad en la mujer está particularmente ligada a su fisiología. Procesos naturales como la menarquia, la pubertad, el embarazo, el parto, la lactancia, la menopausia, la condicionan frecuentemente a sufrir alteraciones mentales verificables no solo psicológicamente como en la histeria (tan parecida a la posesión demoniaca que convoca a más de cinco médicos para discernir la diferencia), sino que también orgánicamente en patologías como hipertrofia del útero, endometritis, amenorrea, epilepsia y otras ya señaladas.

62 Ernestina Pérez, Lecciones de Ginecología. Prefacio del Dr. Leopoldo Landau, Berlín, 1910, 36-37.

63 Hart, op. cit., 818

64 Andrés Laiseca, Informe reproducido en Roa, op. cit., 191. 
No solo la fisiología dispone a la mujer a la enfermedad. La anatomía cerebral femenina está configurada para determinados roles sociales como la maternidad, el cuidado de la familia, la entrega de amor, la contemplación, etc.

El ser mujer es una condición premórbida de la que es prácticamente imposible sustraerse; sin embargo la manifestación del proceso mórbido puede evitarse a través de la educación moral temprana de las niñas y del aprendizaje de los roles sociales para los que está físicamente más apta.

\section{Fuentes DE CONSUlta}

Abalos del Pedregal, Ximena; Bibliografía para el estudio de la historia de la medicina en Chile, Biblioteca de Historia de la Medicina VIII, Centro de Investigaciones de Historia de la Medicina de la U. de Chile, Santiago, 1961.

Anrique, Nicolás; "Bibliografía de las principales revistas y periódicos de Chile", Anales de la Universidad de Chile, Tomo CXV, Santiago, 1904.

Astaburuaga, Ricardo; Fisiognómica: La ciencia del signo y el símbolo, Editorial Universitaria, Santiago, 1978.

Beauvoir, Simone de; El segundo sexo, Ediciones Siglo Veinte, Buenos Aires, 1972.

Beca, Manuel Segundo; "El estado mental en la histeria", Revista Médica de Chile, v. 33, números 3 y 4, Santiago, 1894.

Cruz-Coke Madrid, Ricardo; Historia de la Medicina Chilena, Editorial Andrés Bello, Santiago, 1995.

Cubí y Soler, Mariano; La Frenolojía y sus glorias. Lecciones de Frenolojía, Carlos BaillyBailliere, Madrid, 1853.

Darwin, Charles; El origen del hombre y la selección en relación al sexo, Ediciones Diana, México, 1969.

Díaz, Eloísa; "Breves observaciones sobre la pubertad en la mujer chilena y de las predisposiciones patológicas propias del sexo", Revista Médica de Chile, v. 16, números 7 y 8, Santiago, 1888 .

Duby, George y Perrot, Michelle, Historia de las mujeres. Tomo 8, El siglo XIX. Cuerpo, trabajo y modernidad, Taurus Ediciones, Madrid, 1993.

Foucault, Michel; El nacimiento de la clínica. Una arqueología de la mirada médica, Siglo Veintiuno editores, México, 1997.

Fuentes, Manuel; Lecciones de jurisprudencia médica. Tomo I, Elementos de Anatomía y Fisiología, Lima, 1876.

Hart, Berry y Barbour, A.H. Freeland; Tratado de Ginecología, s/e, Madrid, 1895.

Izquierdo, Vicente; "Una página de Claudio Bernard: de las funciones del cerebro", Revista Médica de Chile, v. 2, números 7 y 8, Santiago, 1874.

Klein, Viola; El carácter femenino. Historia de una ideología, Editorial Paidós, Buenos Aires, 1951.

Körner, Víctor; "Exploración de la mujer", Anales de la Universidad de Chile, t. LXV, 1884.

Lagarde, Marcela; Los cautiverios de las mujeres: madresposas, monjas, putas, presas y locas, Universidad Nacional Autónoma de México, México, 1997. 
Laín Entralgo, Pedro; Medicina e Historia, Ediciones Escorial, Madrid, 1941.

Laqueur, Thomas; La construcción del sexo. Cuerpo y género desde los griegos hasta Freud, Ediciones Cátedra, Madrid, 1994.

Laval, Enrique; "El primer caso psiquiátrico publicado en Chile", Revista Psiquiátrica, vls. 18,19 y 20, Santiago, 1953-1955.

Letelier Grez; Jerónimo; Contribución el estudio de las enfermedades mentales en Chile. Memoria de prueba para optar al grado de Licenciado en la Facultad de Medicina y Farmacia, Valparaíso, 1898.

Luengo, Juan Carlos; Enfermedad mental y aislamiento social. Tesis para optar al grado de licenciado en historia. Departamento de Ciencias Históricas, Facultad de Filosofía, Humanidades y Educación, Universidad de Chile, Santiago, 1986.

Maio, Romeo de; Mujer y Renacimiento, Mondadori, Madrid, 1988.

Márquez Breton, Bernardo; Orígenes del darwinismo en Chile, Editorial Andrés Bello, Santiago, 1982.

Carrol Smith-Rosenberg y Charles Rosenberg, "El animal hembra: puntos de vista médicos y biológicos sobre la mujer y su función en la América del siglo XIX", en Mary Nash ed., Presencia y Protagonismo. Aspectos de la historia de la mujer, Barcelona, Serbal, 1984.

Niceforo, Alfredo; Criminología. Tomo IV. La mujer, biopsicología, delincuencia, prostitución. Las diversas edades de la vida humana, Editorial José María Cajica, Ciudad de Puebla, México, 1954.

Orrego Luco, Augusto; "Causas indirectas de la alucinación mental”, Revista Médica de Chile, número 9, Santiago, 1874.

Orrego Luco, Augusto; "Neurosis Mímicas", Revista Médica de Chile, v. 8, número 3, Santiago, 1879.

Orrego Luco, Augusto; "Observaciones sobre el cerebro de los criminales", Revista Médica de Chile, año VII, Santiago, 1880.

Ortiz Cerda, Ramón; "Influencia del flujo menstrual sobre la salud y enfermedades de la mujer", Revista Médica de Chile, v. 2, números 7, 8 y 9, Santiago, 1874.

Palma Prado, Cristina y Salas Neumann, Emma; "Presencia de la mujer en los estudios superiores de la Universidad de Chile" en AA.VV., Huella y Presencia, Ediciones de la Universidad de Chile, Editorial Universitaria, Santiago, 1992.

Pateman, Carole; The Disorder of Women, Stanford University Press, Stanford, 1989.

Pérez, Ernestina; Lecciones de Ginecología, s/editorial, Berlín, 1910.

Phillips, Inés; "Tesis inéditas de licenciados en Medicina", Anales Chilenos de Historia de la Medicina, Santiago, 1965.

Reale, Giovanni y Antiseri, Darío; Historia del pensamiento filosófico y científico, Editorial Herder, Barcelona, 1995.

Relación hecha al señor Arzobispo por el presbítero don José Raimundo Zisternas sobre las observaciones verificadas en una joven que se dice espirituada, acompañada de los informes de varios facultativos que practicaron sus reconocimientos profesionales, expresando en ellos el juicio que han formado sobre semejante fenómeno. Imprenta del Conservador, Santiago, octubre de 1857.

Riera, Juan; Historia, Medicina y Sociedad, Ediciones Pirámide, Madrid, 1988.

Roa, Armando; "Los cien años de la psiquiatría chilena", Revista del Colegio Médico, Año IV, número 8, Santiago, 1952. 
Roa, Armando; "Rasgos del pensamiento científico en Chile durante el siglo XIX", en Cuadernos de la Universidad de Chile, Santiago, s/año.

Roa, Armando; Demonio y Psiquiatría. Aparición de la conciencia científica en Chile, Editorial Andrés Bello, Santiago, 1974.

Serrano, Sol; Universidad y Nación. Chile en el siglo XIX, Editorial Universitaria, Santiago, 1994.

Spencer, Herberto; La educación intelectual, moral y física, D. Appleton y Compañía, Londres, 1912.

Stuven, Ana María; "Modernidad y Religión en Chile. La imagen de la mujer y su rol social durante el siglo XIX", 14as Jornadas de Historia de Chile, Santiago, 2001.

Subercaseaux, Bernardo; Historia de las ideas y de la cultura en Chile, Editorial Universitaria, Santiago, 1997.

Vicuña Navarro, Miguel; La emergencia del positivismo en Chile, Universidad Arcis, Centro de Investigaciones Sociales, Santiago, 1997.

Fecha de recepción: marzo de 2005.

Fecha de publicación: junio de 2006. 